\title{
ARTIKEL_SAKTIATI.docx by
}

Submission date: 08-Jun-2021 09:20AM (UTC+0700)

Submission ID: 1602552211

File name: ARTIKEL_SAKTIATI.docx (57.38K)

Word count: 2318

Character count: 15784 


\title{
Sumber Daya Dalam Pelayanan Paket C Akta Kematian di Dinas Kependudukan dan Pencatatan Sipil Kabupaten Sidoarjo
}

Saktiati ${ }^{1}$, Lailul Mursyidah ${ }^{2}$

Program Studi Administrasi Publik, Fakultas Bisnis, Hukum, dan Ilmu Sosial

Universitas Muhammadiyah Sidoarjo

*Email : sakti.ati12@gmail.com, lailulmursyidah@umsida.ac.id

\begin{abstract}
The purpose of this research is to describe and analyze the service package c death certificate at the Department of Population and Civil Registration of Sidoarjo Regency. This study used a qualitative type method approach which took place in the Sidoarjo District Civil Service Office as the location of the research. This research is presented with data collection techniques through observation, interviews, and documentation. The technique of determining the informants used purposive sampling, and data analysis was carried out by data collection techniques, data reduction, data presentation, and conclusions or verification. The results of this study use the theory of public service quality which can be seen from the unfulfilled resources of the Sidoarjo Ministry of Civil Service and Civil Service, based on a review of several dimensions such as Tangible, which shows a lack of employees in the issuance of death certificates and insufficient sarpras, Reliability. (Reliability) there are SOPs stated in the Perbup), Responsiviness (Response) becomes less than optimal because the number of employees in the publishing division is only 2 (two) people and the applicant is 40 people each day, the Sidoarjo Dispendukcapil Assurance issues death certificates, $K K, K T P$, and Emphaty (Empathy) can be seen from the services that have met the service standards of the OPD (Regional Apparatus Organization), but it is necessary to add additional employees in the publishing department so that the service can be maximized.
\end{abstract}

Keywords: Quality of Service, Population Service, Package C Death Certificate

Abstrak: Tujuan pada penelitian ini adalah untuk mendeskripsikan dan menganalisis pelayanan paket c akta kematian di Dinas Kependudukan dan Pencatatan Sipil Kabupaten Sidoarjo. Penelitian ini menggunakan pendekatan metode jenis kualitiatif dengan bertempat di Dispendukcapil Kabupaten Sidoarjo sebagai lokasi penelitiannya. Penelitian ini disajikan dengan teknik pengumpulan data melalui observasi, wawancara, dan dokumentasi. Teknik penentuan informan menggunakan purposive sampling, serta penganalisaan data dilakukan dengan teknik pengumpulan data, reduksi data, penyajian data, dan kesimpulan atau verifikasi. Hasil penelitian ini menggunakan teori kualitas pelayanan publik yang terlihat dari sumber daya Dispendukcapil Sidoarjo yang belum terpenuhi pada pelayanan paket $\mathrm{c}$ akta kematian, berdasarkan tinjauan beberapa dimensi seperti, Tangible (Berwujud) menunjukkan kurangnya pegawai pada bagian penerbitan akta kematian dan sarpras yang kurang memenuhi, Reliability (Kehandalan) terdapat SOP yang tertuang pada Perbup), Responsiviness (Respon/Ketanggapan) menjadi kurang maksimal karena jumlah pegawai bagian penerbitan hanya 2 (dua) orang dan pemohon berjumlah 40 orang tiap harinya, Assurance (Jaminan) Dispendukcapil Sidoarjo menerbitkan akta kematian, KK, KTP, dan Emphaty (Empati) terlihat dari pelayanan yang telah memenuhi standar pelayanan OPD (Organisasi Perangkat Daerah), namun dibutuhkan penambahan pegawai bagian penerbitan agar pelayanan menjadi maksimal.

Kata Kunci : Kualitas Pelayanan, Pelayanan Kependudukan, Paket C Akta Kematian 


\section{PENDAHULUAN}

Pelayanan publik merupakan rangkaian kegiatan yang dilaksanakan penyelenggara pelayanan publik sebagai upaya pemenuhan kebutuhan dasar hak-hak setiap penerima pelayanan publik. Penerima pelayanan publik disini adalah seluruh warga 17 ara atau masyarakat umum. Penyelenggaran pelayanan publik salah satunya adalah instansi pemerintahan. Dalam Undang-Undang No. 25 Tahun 2009 tentang Pelayanan Publik dikatakan Pelayanan Publik adalah kegiatan atau rangkaian kegiatan dalam rangka pemenuhan kebutuhan pelayanan sesuai dengan peraturan perundang undangan bagi setiap warga negara dan penduduk atas barang, jasa, dan/atau pelayanan administratif yang disediakan oleh penyelenggara pelayanan publik. Pelayanan publik harus dilakukan secara efisien. Salah satu visi dari otonomi daerah adalah mengetahui persoalan dan kebutuhan dari masyarakat [1].

Kualitas pelayanan publik yang baik merupakan tujuan utama pemerintah dalam penyelenggaraan pelayanan publik. Pelayanan dikatakan efektif apabila masyarakat mendapat kemudahan pelayanan dengan prosedur yang jelas $2^{\text {hgkat, }}$ cepat, tepat dan memuaskan. Kepuasan masyarakat menjadi indikator pentin 2 dalam pemenuhan kebutuhan masyarakat untuk kemudian menciptakan inovasi dan strategi pelayanan yang efisien. Kualitas pelayanan ini "diukur" menggunakan 5 dimensi yaitu, tangible (bukti fisik), reliability (keandalan), responsiveness (daya tanggap), assurance (jaminan), dan empathy (empati) [2].

Salah satu bentuk layanan instansi pemerintah 1 adalah administrasi kependudukan. Menurut Undang-Undang Nomor 24 Tahun 2013 tentang Perubahan Atas Undang-Undang Nomor 23 Tahun 2006 tentang Administrasi Kependudukan merupakan rangkaian kegiatan penataan dan penertiban dalam penerbitan dokumen dan data kependudukan melalui pendaftaran penduduk, pencatatan sipil, pengelolaan informasi administrasi kependudukan serta pendayagunaan hasilnya untuk pelayanan publik dan pembangunan sektor lain. Tujuan utama penyelenggaraan kegiatan administrasi kependudukan adalah terwujudnya tertib administrasi kependudukan adanya kejelasan bukti diri dan kepastian hukum tentang peristiwa dan status kependudukan yang lengkap cakupannya, akurat, handal, serta mampu menggambarkan karakteristik penduduk 23 ].

Pelayanan administrasi kependudukan ini meliputi pembuatan Kartu Keluarga (KK) Kartu Tanda Penduduk Elektronik (e-KTP), surat pindah, dan Kartu Identitas Anak (KIA) sedangkan pencatatan sipil meliputi pembuatan kutipan akta kelahiran, kutipan akta kematian, kutipan akta perkawinan, kutipan akta perceraian, pencatatan pengakuan anak dan pengesahan anak pencatatanperubahan nama pencatatanperubahan status anak, dan pencatatan perubahan kew 5 ganegaraan. Salah satu bentuk pelayanan administrasi kependudukan adalah pengurusan pencatatan akta kematian. Hal ini diatur dalam pasal Ayat 44 (1) Undang-undang Nomor 24 Tahun 2013 tentang perubahan atas Undang-undang Nomor 23 Tahun 2006 tentang administrasi kependudukan yang berbunyi: "Setiap kematian wajib dilaporkan oleh ketua rukun tetangga datau nama lainnya di domisili penduduk kepada Instansi Pelaksana setempat paling lambat 30 (tiga puluh) hari sejak tanggal kematian. Manfaat dari pelaporan kematian yakni untuk keperluan pemerintah dalam sistem akurasi data kependudukan, serta dalam pengurusan ahli waris, pengurusan taspen serta perubahan status seseorang.

Dinas Kependudukan dan Pencatatan Sipil Kabupaten Sidoarjo (Dispendukcapil) merupakan salah satu lembaga pemerintahan yang melaksanakan pelayanan p(1) lik yang mempunyai tugas dan kewenangan untuk menerbitkan akta kematian. Untuk melaksanakan kewenangan tersebut Pemerintahan Kabupaten Sidoarjo mengeluarkan Peraturan Bupati Nomor 41 Tahun 2016 Tentang Paket Layanan Administrasi Kependudukan dan Pencatatan Sipil, dimana dalam Peraturan Bupati tersebut terdapat 3 paket diantaranya adalah: Paket A (akta perkawinan), Paket B (akta perceraian), Paket C (akta kematian) [4].

Dalam pelayanan paket $\mathrm{c}$ akta kematian di Dispendukcapil Kabupaten Sidoarjo menunjukkan beberapa permasalahan seperti, sumber daya yang kurang memadai, membuat pelayanan memakan waktu cukup lama Berdasarkan melihat tabel hasil rekapitulasi jumlah pembuatan Akta Kematian di Kabupaten Sidoarjo di bawah ini. 
Tabel 1.1

Rekapitulasi Akta Kematian Kabupaten Sidoarjo

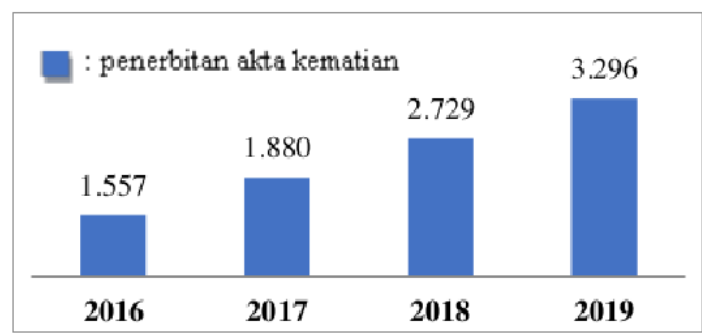

Sumber: Dinas Kependudukan dan Pencatatan Sipil Kabupaten Sidoarjo (2019)

Tabel 1.1 rekapitulasi akta kematian Kabupaten Sidoarjo, menunjukkan kenaikan sekitar 300-800 akta kematian yang diterbitkan oleh Dispendukcapil Kabupaten Sidoarjo sepanjang tahun 2016 hingga 2019. Tabel tersebut, juga memaparkan adanya antusias atau partisipasi dari masyarakat sebagai pemohon terkait layanan Paket C Akta Kematian. Sehingga, pada setiap tahunnya jumlah pemohon dan penerbitan akta kematian menjadi bertambah. Akan tetapi, menurut hasi1 wawancara dengan Kepala Dispendukcapil Sidoarjo Bapak Drs. Medi Yulianto, MSi terdapat kend 6la kurangnya tenaga pegawai yang terkadang menjadi implementasi paket layanan tersebut tidak efektif [5].

Berdasarkan Undang-undang No. 23 Tahun 2014 tentang Pemerintahan Daerah dan Peraturan Pemerintah No. 17 Tahun 2018 tentang Kecamatan menyatakan bahwa Kecamatan berkedudukan sebagai bagian wilayah dari Kabupaten/Kota yang dipimpin oleh seorang camat yang memiliki kedudukan sebagai kepala perangkat daerah di kecamatan dan pelaksana urusan pemerintahan umum di wilayah kecamatan salah satunya adalah pelayanan terpadu penerb $4 \mathrm{n}$ Kartu Keluarga bagi keluarga almarhum yang ditinggalkan. Dalam hal ini, adanya tumpang tindih tupoksi antara Dinas Kependudukan dan Pencatatan Sipil Kabupaten Sidoarjo dengan kecamatan. Maka dari itu, penelitian ini diharapkan dapat mendiskripsikan dan menganalisis pelayanan paket c akta kematian di Dinas Kependudukan dan Pencatatan Sipil Kabupaten Sidoarjo Timur [6].

\subsection{Kualitas Pelayanan Publik}

\section{TINJAUAN PUSTAKA}

Kualitas pelayanan merupakan bahasan yang penting dalam penyelenggaraan penyedia pelayanan publik. Lembaga pemerintah semakin dituntut untuk menciptakan kualitas pelayanan yang dapat memberikan dampak positif untuk tingkat kepuasan masyarakat. Kualitas pelayanan publik menurut Fandy Tjiptono 2005 adalah suatu kondisi dinamis yang berhubungan dengan produk, jasa, manusia, proses, dan lingkungan yang memenuhi atau melebihi harapan. Menurut Zeithaml dkk (Hardiyansyah, 2011:46) dalam Kualitas Pelayanan Publik mengemukakan kualitas pelayanan dapat diukur dari 5 dimensi yang didalamnya terdapat indikator-indikator sebagai berikut: tangible (bukti fisik), reliability (keandalan), responsiveness (daya tanggap), assurance (jaminan), dan empathy (empati) [7].

\subsection{Administrasi Kependudukan}

Definisi administrasi menurut Siagian dalam Susiani (2019:2) menyatakan bahwa, "Administrasi adalah keseluruhan proses kerjasama antara dua orang manusia atau lebih didasarkan rasionalitas tertentu untuk mencapai tujuan yang ditentukan sebelumnya." Tujuan dari adanya administrasi kependudukan yaitu guna tertib dalam rangka penerbitan database kependudukan, penerbitan NIK, dan penerbitan dokumen kependudukan. Sedangkan, menurut Soemartono dan Hendrastuti (2011:57-153) menuliskan bahwa administrasi kependudukan terbagi menjadi 2 (dua) jenis yaitu: Pendaftaran Penduduk terbagi menjadi 5 (lima) macam dan Pencatatan Sipil terbagi menjadi 11 (sebelas) macam [8]. 


\subsection{Paket C}

Paket C merupakan proses pelayanan penerbitan akta kematian sekaligus diterbitkan Kartu Keluarga (KK) bagi anggota keluarga almarhum dalam satu Kartu Keluarga (KK) dan Kartu Tanda Penduduk Elektronik (KTP-el) bagi suami/istri almarhum sesuai dengan perubahan elemen data kependudukan karena kematian. Paket Layanan ini mempermudah masyara $3 t$ dikarenakan dalam pengurusannya membutuhkan waktu yang lebih singkat yaitu selama 10 (sepuluh) hari kerja. Akta kematian adalah suatu akt 3 ang dibuat dan diterbitkan oleh Dinas Kependudukan yang membuktikan secara pasti tentang kematian seseorang. Dalam Undang-undang Nomor 24 Tahun 2013 Pasal 44 ayat (1) menyatakan bahwa Setiap kematian wajib dilaporkan oleh ketua rukun tetangga atau nama lainnya di domisili Penduduk kepada Ins 4 lisi Pelaksana setempat paling lambat 30 (tiga puluh) hari sejak tanggal kematian. Selain itu terdapat dasar hukum Peraturan Daerah Kabupaten Sidoarjo Nomor 2 Tahun 2015 tentang Perubahan Atas Peraturan Daer 3 Nomor 1 Tahun 2008 tentang Penyelenggaran Administrasi Kependudukan Kabupaten Sidoarjo [9].

Kematian merupakan salah satu peristiwa penting yang dialami oleh setiap orang yang harus dicatat dan dikukuhkan oleh negara dalam bentuk Akta Kematian. Akta kematian adalah akta yang ditandatangani dan diterbitkan oleh pejabat Dinas Kependudukan dan Pencatatan Sipil sebagai bukti administrasi kematian seseorang. Kematian seseorang harus segera dilaporkan agar dihapus dari daftar kependudukan. Manfaat dibuatnya suatu akta kematian yaitu untuk mengurus penetapan ahli waris dalam penentuan status hukum seseorang, pengurusan pensiun bagi janda/duda, pengurusan klaim asuransi, persyaratan perkawinan kembali, santuan uang duka dan lain sebagainya. Selain itu, dibuatnya suatu akta kematian bertujuan untuk mencegah seseorang menyalahgunakan data almarhum oleh pihak yang tidak bertanggung jawab.

\section{METODE PENELITIAN}

Penelitian ini menggunakan pendekatan penelitian kualitatif. Menurut Sugiyono (2013) menyatakan bahwa penelitian deskriptifialah penelitian yang dilaksanakan untuk mencari tahu variabel mandiri baik satu variabel maupun lebih dari satu variabel (independent) tanpa adanya sebuah perbandingan, ataupun mengkaitkan dengan variabel yang lain. Dipilihnya jenis deskriptif ini seba lebih memberikan paparan yang jelas tentang suatu permasalahan yang sedang diteliti [10]. Maka itu, penelitian ini bermaksud untuk memberikan pemahaman, penjelasan, dan gambaran berupa deskipsi mengenai pelayanan paket c akta kematian di Dinas Kependudukan dan Pencatatan Sipil Kabupaten Sidoarjo Timur.

\subsection{Hasil Penelitian}

\section{HASIL PENELITIAN DAN PEMBAHASAN}

Berdasarkan hasil wawancara dengan beberapa informan penelitian pelayanan paket $\mathrm{c}$ akta kematian di Dinas Kependudukan dan Pencatatan Sipil Kabupaten Sidoarjo Timur, yaitu Kepala Bidang Pelayanan Pencatatan Sipil Dinas Kependudukan dan Pencatatan Sipil Kabupaten Sidoarjo, Kepala Seksi Bidang Perubahan Status Anak, Pewarganegaraan dan Kematian (Dispendukcapil) Kabupaten Sidoarjo, dan masyarakat atau pemohon pelayanan Paket C Akta Kematian. Pelaksanaan penelitian dilakukan selama kurang lebih enam bulan, dengan mendatangi lokasi penelitian dimana penulis melakukan wawancara secara mendalam (2)gan informan di kantor Dispendukcpil Kabupaten Sidoarjo. Sebagai panduan wawancara menggunakan teori kualitas pelayanan publik, seperti tangible (bukti fisik), reliability (keandalan), responsiveness (daya tanggap), assurance (jaminan), dan empathy (empati). Namun, diantara kelima dimensi tersebut yang memunculkan sebuah permasalahan sesuai kondisi lapangan adalah dimensi tangible (bukti fisik).

\subsection{Dimensi Tangible (bukti fisik)}

Bentuk wujud dari kualitas paket $\mathrm{C}$ adalah ruang pelayanan Dispendukcapil Sidoarjo yang kurang luas, disebabkan dari kurangnya kesadaran dari pemohon yang mengajak masuk pengantar untuk menunggu layanan Paket C Akta Kematian di ruangan. Selain itu, penempatan sarpras penunjang lain seperti, penempatan papan pengumunan dan informasi yang kurang tepat yaitu berada di area parkiran. Maka dari itu, sulit diketahui oleh pemohon. Kemudian 
proses penerbitan akta kematian selama 7 (tujuh) hari masa kerja dikarenakan pegawai pada bagian tersebut hanya berjumlah hanya 2 (dua) orang dan pemohon berjumlah 40 orang tiap harinya. Sehingga, kuantitas dan kualitas dari pegawai serta sarana prasarana pendukung Dispendukcapil Sidoarjo perlu ditingkatkan demi memenuhi kebutuhan untuk meningkatkan kualitas pelayanan.

\subsection{Pembahasan Hasil Penelitian}

Berdasarkan hasil penelitian di lapangan telah ditemukan masalah terkait sumber daya pegawai dan fasilitas atau sarana dan prasarana pelayanan Paket C Akta Kematian di Dispendukcapil Kabupaten Sidoarjo kurang terpenuhi. Selain itu, jumlah petugas bagian penerbitan akta kematian yang kurang memadai, mengakibatkan penyelesaian akta kematian memakan waktu yang cukup lama.

\section{KESIMPULAN}

1. Kesimpulan

Berdasarkan temuan hasil penelitian dan pembahasan yang telah dipaparkan dapat di tarik kesimpulan sebagai berikut :

Sumber daya dalam pelayanan paket c akta kematian di Dinas Kependudukan dan Pencatatan Sipil Kabupaten Sidoarjo yang di sesuaikan dengan kondisi di lapangan, menarik kesimpulan bahwa di pelayanan paket c akta kematian ditinjau dari dimensi tangible (bukti fisik) belum maksimalnya sarana dan prasarana pelayanan dan pegawai bagian penerbitan akta kematian yang kurang memadai.

\section{Saran}

Sumber daya dalam pelayanan paket c akta kematian di Dinas Kependudukan dan Pencatatan Sipil Kabupaten Sidoarjo perlu penambahan staff atau pegawai. Jika rekrumen pegawai honor dirasa banyak mengeluarkan biaya operasional, sebaiknya membuka peluang untuk mahasiswa/i universitas yang berada di Sidoarjo untuk mengikuti magang agar mendapat pengalaman dan dapat membantu pegawai Dispendukcapil Kabupaten Sidoarjo pada bagian penerbitan akta kematian. Selain itu, fasilitas berupa ruang pelayanan Dispendukcapil Sidoarjo yang kurang luas dan penempatan sarpras penunjang lain kurang tepat. Diharapan Dispendukcapil Sidoarjo mengingatkan atau membuat pengumuman untuk yang memasuki ruang pelayanan di khususkan hanya untuk pemohon dan untuk pengantar diharapkan tidak menunggu di area Dispendukcapil.

\section{REFERENSI}

[1] Undang-Undang No. 25 Tahun 2009 tentang Pelayanan Publik

[2] Hardiansyah, Dr. (2011). Kualitas Pelayanan Publik: Konsep, Dimensi, Indikator, dan Implementasinya. Gava Media. Yogyakarta.

[3] Undang-Undang Nomor 24 Tahun 2013 tentang Perubahan Atas Undang-Undang Nomor 23 Tahun 2006 tentang Administrasi Kependudukan

[4] Peraturan Bupati Nomor 41 Tahun 2016 Tentang Paket Layanan Administrasi Kependudukan dan Pencatatan Sipil [5]Dispendukcapil (2019) "Dinas Kependudukan dan Pencatatan Sipil Kabupaten Sidoarjo". http:// dispendukcapil.go.id (diakses 03 Januari 2019)

[6] Undang-Undang Nomor 23 Tahun 2014 tentang Pemerintahan Daerah

[7] Tjiptono, Fandy. (2005). Kualitas Pelayanan Publik. Gava Media: Yogyakarta.

[8] 4 lagian. (2019). Administrasi: Kependudukan. Bumi Aksara: Jakarta.

[9] Peraturan Daerah Kabupaten Sidoarjo Nomor 2 Tahun 2015 tentang Perubahan Atas Peraturan Daerah Nomor 1

Tahun 2008 tentang Penyelenggaran Administrasi Kependudukan Kabupaten Sidoarjo.

[10] Sugiyono. 2013. Metode Penelitian Kuantitatif Kualitatif R\&D. Alfabeta: Bandung. 


\section{ARTIKEL_SAKTIATI.docx}

ORIGINALITY REPORT

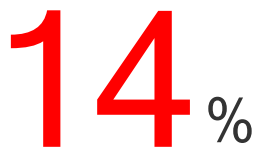

SIMILARITY INDEX

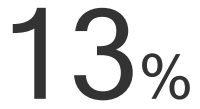

INTERNET SOURCES
$7 \%$

PUBLICATIONS
$12 \%$

STUDENT PAPERS

PRIMARY SOURCES

1 jurnalmahasiswa.unesa.ac.id

Internet Source

$3 \%$

eprints.uny.ac.id

Internet Source

$3 \%$

text-id.123dok.com

Internet Source

$2 \%$

digilib.uinsby.ac.id

Internet Source

digilib.unila.ac.id

Internet Source

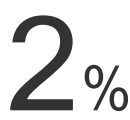

radarjonggol.com

Internet Source

core.ac.uk

Internet Source 